\title{
TRANSPARENCIA DE LA FUNCIÓN PÚBLICA Y ACCESO A LA INFORMACIÓN DE LA ADMINISTRACIÓN DEL ESTADO: UNA NORMATIVA PARA CHILE
}

\author{
TRANSPARENCY IN EXECUTIVE POWER AND GOVERNMENT \\ ADMINISTRATION ACCESS: A NEW CHILEAN'S LEGAL RULE
}

\section{ÁNGELA Vivanco MarTíneZ ${ }^{1}$}

Una de las reformas más importantes que se concretaron el año 2005, respecto de la Carta Fundamental de 1980, fue la introducción de un nuevo artículo $8^{\circ}$, en el cual se reconocían como Bases de la Institucionalidad el respeto al "el principio de probidad" para todas las actuaciones de los órganos del Estado y la calidad de "públicos" de los actos y resoluciones de dichos órganos, "así como sus fundamentos y los procedimientos que utilicen". Además, la norma disponía que "solo una ley de quórum calificado podrá establecer la reserva o secreto de aquellos o de estos, cuando la publicidad afectare el debido cumplimiento de las funciones de dichos órganos, los derechos de las personas, la seguridad de la Nación o el interés nacional".

La calificación de importancia que acabamos de hacer no solo corresponde a lo novedoso del texto transcrito para una constitución chilena, sino al hecho que significaba, a nuestro juicio, una toma de postura del Constituyente sobre un tema largamente debatido y fuertemente controversial a lo largo de toda nuestra historia democrática, recogido y evidenciado además en numerosos casos entregados a los tribunales de justicia: cómo ha de resolverse la tensión o conflicto entre el derecho a saber del público sobre aquello que es precisamente de su legítimo interés y la pre-

\footnotetext{
1 Licenciada en Derecho, Pontificia Universidad Católica de Chile; Candidata a Doctor en Derecho por la Universidad de La Coruña, España. Profesora de Derecho Constitucional y de Derecho de la Comunicación de la Facultad de Derecho de la Pontificia Universidad Católica de Chile.
}

rrogativa del Estado de guardar para sí cierta información por motivos plausibles.

En efecto, el Constituyente derivado de 2005 optó por materializar tres premisas básicas que hoy han de considerarse como componentes esenciales de todo régimen democrático, para resolver tal controversia o diferendo: La probidad no puede ser considerada como tal si no se la asocia a la transparencia, es decir, a la voluntad permanente de decidir sobre la cosa pública abiertamente, permitiendo que los ciudadanos conozcan los fundamentos y las razones de la decisión, además de cómo esta se ejecuta; tal cosa importa que el acceso a la información pública deje de ser una prerrogativa concedida por la autoridad y se reconozca y garantice como un derecho de todas las personas, esencial por lo demás para el ejercicio de otras muchas garantías contempladas en la Constitución y, por último, en el contexto referido, que el secreto o la reserva de una determinada información se rija por pautas objetivas establecidas en la ley y no determinadas arbitrariamente por quien tiene a su cargo el registro o antecedentes necesarios.

Pese a tal avance constitucional, sin embargo, la situación legislativa del país demandaba hacer ajuste para poder dar aplicación al referido precepto constitucional, el cual si bien podía invocarse directamente en sede de inaplicabilidad, por ejemplo, encontraba ciertas cortapisas materiales para su plena materialización, ya que no solo se trataba de sostener filosóficamente estos principios o de pretender cumplir con ellos, sino de la asignación de recursos y del establecimiento de una orgánica y de unos procedimientos para cautelar que la mecánica del acceso a la infor- 
mación pública efectivamente se concretara. Esa fue la pretensión que se tuvo a la vista cuando, mediante varias indicaciones sustitutivas de la Presidencia de la República, se utilizó el texto de la moción parlamentaria iniciada por los senadores señores Jaime Gazmuri Mujica y Hernán Larraín Fernández, contenida en el Boletín No 3773-06 y presentada en el Senado de la República en enero de 2005, para establecer una normativa regulatoria de estas materias que fuera compatible con la reforma constitucional aprobada durante el mismo año. Sin embargo, para ser justos con el desarrollo histórico del tema, la verdad es que el verdadero impulso del asunto se produjo cuando, el 11 de septiembre de 2006, la Corte Interamericana de Derechos Humanos (CIDH) falló en contra de Chile por el caso Claude Reyes y Otros", en atención a la negativa del Comité de Inversiones Extranjeras de entregar información ambiental, reconociendo el derecho de acceso a información pública, como derecho humano fundamental y componente esencial del fortalecimiento democrático, lo cual motivó un fuerte interés del Ejecutivo en que la normativa del caso viera definitivamente la luz².

A la fecha de cierre de esta edición de la Revista Chilena de Derecho, la promulgación de la Ley de transparencia de la función pública y de acceso a la información de la Administración del Estado es inminente, tras el fallo del Tribunal Constitucional de fecha 10 de julio de $2008^{3}$ que consideró constitucional la gran mayoría del articulado sometido a su control preventivo y el oficio de ley enviado al Ejecutivo el 15 de julio de 2008 con el texto definitivo del proyecto aprobado.

El proyecto que será pronto ley de la República y que, en consecuencia, habrá de entenderse como un complemento esperamos eficaz al artículo $8^{\circ}$ de la Constitución, contiene los siguientes elementos destacables:

\footnotetext{
2 El texto completo del fallo se encuentra en http:// www.corteidh.or.cr $/$ casos.cfm?idCaso $=245$, sitio consultado en agosto de 2008.

3 El texto completo del fallo se encuentra en http://sil.congreso.cl/cgi-bin/sil_abredocumentos. pl?3,13296, sitio consultado en agosto de 2008.
}

\section{APLICACIÓN DE LA LEY}

De acuerdo a su Artículo $2^{\circ}$, las disposiciones de la ley serán aplicables "a los ministerios, las intendencias, las gobernaciones, los gobiernos regionales, las municipalidades, las Fuerzas Armadas, de Orden y Seguridad Pública, y los órganos y servicios públicos creados para el cumplimiento de la función administrativa". Además, "La Contraloría General de la República y el Banco Central se ajustarán a las disposiciones de esta ley que expresamente esta señale, y a las de sus respectivas leyes orgánicas" en estas materias.

Respecto de las empresas, "se aplicarán las disposiciones que esta ley expresamente señale a las empresas públicas creadas por ley y a las empresas del Estado y sociedades en que este tenga participación accionaria superior al 50\% o mayoría en el directorio".

Como queda en evidencia de estos preceptos, el proyecto no hace referencia, como podría pensarse inicialmente, a la información pública entendida como toda aquella que reviste legítimo interés para el público, sino fundamentalmente a la que obra en poder, ilustra la decisión y sirve como fundamento a la gestión de las entidades antes señaladas, incluidas las empresas de participación estatal, lo cual sigue el lenguaje restrictivo del propio artículo $8^{\circ}$. Ello nos lleva a dirigirnos, respecto de la restante información de interés público y teniendo a la vista esta vez el artículo $5^{\circ}$ de nuestra Carta Fundamental, más bien a lo dispuesto en la Convención Americana de Derechos Humanos, Pacto de San José de Costa Rica, en su artículo 13, la cual contempla el derecho de toda persona a "la libertad de pensamiento y de expresión", derecho que "comprende la libertad de buscar, recibir y difundir informaciones e ideas de toda índole", el cual "no puede estar sujeto a previa censura sino a responsabilidades ulteriores, las que deben estar expresamente fijadas por la ley y ser necesarias para asegurar: a) el respeto a los derechos o a la reputación de los demás, o b) la protección de la seguridad nacional, el orden público o la salud o la moral públicas". 


\section{PRINCIPIO DE TRANSPARENCIA DE LA FUNCIÓN PÚBLICA}

El artículo $4^{\circ}$ del Proyecto dispone que "Las autoridades, cualquiera que sea la denominación con que las designen la Constitución y las leyes, y los funcionarios de la Administración del Estado, deberán dar estricto cumplimiento al principio de transparencia de la función pública", el cual consiste en "respetar y cautelar la publicidad de los actos, resoluciones, procedimientos y documentos de la Administración, así como la de sus fundamentos, y en facilitar el acceso de cualquier persona a esa información, a través de los medios y procedimientos que al efecto establezca la ley".

El interés de esta definición de transparencia, radica a nuestro entender en que se ha recogido expresamente el mandato del Constituyente, en el sentido que no se trata solo de hacer público aquello que los órganos del Estado deciden, sino la forma y los antecedentes de estas decisiones, elementos en los que más comúnmente debemos afrontar la opacidad de ciertos organismos y, como consecuencia, las dificultades de escrutinio de su actuar por parte de los destinatarios de sus resoluciones o actos.

El artículo $5^{\circ}$ del proyecto refuerza esta idea, al agregar que "En virtud del principio de transparencia de la función pública, los actos y resoluciones de los órganos de la Administración del Estado, sus fundamentos, los documentos que les sirvan de sustento o complemento directo y esencial, y los procedimientos que se utilicen para su dictación, son públicos, salvo las excepciones que establece esta ley y las previstas en otras leyes de quórum calificado", haciendo una precisión luego que no es casual y que expande la cobertura del legislador en esta materia: "Asimismo, es pública la información elaborada con presupuesto público y toda otra información que obre en poder de los órganos de la Administración, cualquiera sea su formato, soporte, fecha de creación, origen, clasificación o procesamiento, a menos que esté sujeta a las excepciones señaladas".

Resulta atractivo pensar, una vez que esta normativa se encuentre vigente, cuánta información es elaborada con presupuesto estatal a través de asesorías, diversas contrataciones, asignaciones o incluso fondos concursables, que podría comprenderse en el concepto anterior.

\section{TRANSPARENCIA ACTIVA}

Dispone el Artículo $7^{\circ}$ que "los órganos de la Administración del Estado señalados en el artículo $2^{\circ}$, deberán mantener a disposición permanente del público, a través de sus sitios electrónicos, los siguientes antecedentes actualizados, al menos, una vez al mes: a) Su estructura orgánica, b) Las facultades, funciones y atribuciones de cada una de sus unidades $u$ órganos internos, c) El marco normativo que les sea aplicable, d) La planta del personal y el personal a contrata y a honorarios, con las correspondientes remuneraciones, e) Las contrataciones para el suministro de bienes muebles, para la prestación de servicios, para la ejecución de acciones de apoyo y para la ejecución de obras, y las contrataciones de estudios, asesorías y consultorías relacionadas con proyectos de inversión, con indicación de los contratistas e identificación de los socios y accionistas principales de las sociedades o empresas prestadoras, en su caso, f) Las transferencias de fondos públicos que efectúen, incluyendo todo aporte económico entregado a personas jurídicas o naturales, directamente o mediante procedimientos concursales, sin que estas o aquellas realicen una contraprestación recíproca en bienes o servicios, g) Los actos y resoluciones que tengan efectos sobre terceros, h) Los trámites y requisitos que debe cumplir el interesado para tener acceso a los servicios que preste el respectivo órgano, i) El diseño, montos asignados y criterio de acceso a los programas de subsidios y otros beneficios que entregue el respectivo órgano, además de las nóminas de beneficiarios de los programas sociales en ejecución -con exclusiones de datos sensibles-, j) Los mecanismos de participación ciudadana, en su caso, k) La información sobre el presupuesto asignado, así como los informes sobre su ejecución, en los términos previstos en la respectiva Ley de Presupuestos de cada año, l) Los resultados de las auditorías 
al ejercicio presupuestario del respectivo órgano $y$, en su caso, las aclaraciones que procedan, y m) Todas las entidades en que tengan participación, representación e intervención, cualquiera sea su naturaleza y el fundamento normativo que la justifica.

Entendemos que esta extensa y rica enumeración importa una tarea bastante ardua respecto de las plataformas que habrán de abrirse y operarse en las entidades y servicios correspondientes, para lo cual hay un plazo de puesta en marcha dispuesto en el mismo proyecto de ley. Sin embargo, nos asiste la duda respecto a cómo podrán cumplir los servicios con su presupuesto ordinario frente a estas exigencias y mucho más un sistema municipal ya de por sí desbalanceado presupuestariamente y con realidades muy disímiles de una comuna a otra, más aún al observar que el proyecto exige que la información anterior se incorpore "en los sitios electrónicos en forma completa y actualizada, y de un modo que permita su fácil identificación y un acceso expedito. Aquellos órganos y servicios que no cuenten con sitios electrónicos propios, mantendrán esta información en el medio electrónico del ministerio del cual dependen o se relacionen con el Ejecutivo, sin perjuicio de lo cual serán responsables de preparar la automatización, presentación y contenido de la información que les corresponda".

\section{DERECHO DE TODA PERSONA A SOLICITAR INFORMACIÓN}

De acuerdo al Artículo 10 del Proyecto "Toda persona tiene derecho a solicitar y recibir información de cualquier órgano de la Administración del Estado, en la forma y condiciones que establece esta ley", lo cual comprende "el derecho de acceder a las informaciones contenidas en actos, resoluciones, actas, expedientes, contratos y acuerdos, así como a toda información elaborada con presupuesto público, cualquiera sea el formato o soporte en que se contenga, salvo las excepciones legales".

Note el lector que en esta materia no solo han de considerarse las excepciones previstas en el propio proyecto, sino en las leyes en general, lo cual sin duda hace referencia específica a materias relacionadas por ejemplo con la acción jurisdiccional del Estado, incluida su Justicia Constitucional y Electoral, la cual quedaría de otro modo intervenida por facultades que importan una orgánica relacionada con el Ejecutivo como se verá, cosa que se consideró expresamente en el fallo del Tribunal Constitucional en su considerando cuadragésimo cuarto: "no resulta aplicable al Ministerio Público, al Tribunal Constitucional, ni al Tribunal Calificador de Elecciones lo dispuesto en el artículo $8^{\circ}$ del Título III de la Ley de Transparencia de la Función Pública y de Acceso a la Información de la Administración del Estado, por cuanto la autonomía que la Constitución ha asignado a ciertos órganos del Estado, como los recién mencionados, y que se proyecta en una triple dimensión -organizativa, institucional y normativa- implica, precisamente, que cada uno de estos ámbitos de acción no puede estar supeditado, en su ejercicio, a órganos que se relacionen, aunque sea en forma indirecta, con las labores de gobierno y administración propias de la función ejecutiva”.

El derecho de acceso a la información de los órganos de la Administración del Estado reconoce, de acuerdo al Artículo 11 y entre otros, los siguientes principios: a) Principio de la relevancia, conforme al cual se presume relevante toda información que posean los órganos de la Administración del Estado, cualquiera sea su formato, soporte, fecha de creación, origen, clasificación o procesamiento, b) Principio de la libertad de información, de acuerdo al que toda persona goza del derecho a acceder a la información que obre en poder de los órganos de la Administración del Estado, con las solas excepciones o limitaciones establecidas por leyes de quórum calificado, c) Principio de apertura o transparencia, conforme al cual toda la información en poder de los órganos de la Administración del Estado se presume pública, a menos que esté sujeta a las excepciones señaladas, d) Principio de máxima divulgación, de acuerdo al que los órganos de la Administración del Estado deben proporcionar información en los términos más amplios posibles, excluyendo solo aquello que 
esté sujeto a las excepciones constitucionales o legales, e) Principio de la divisibilidad, conforme al cual si un acto administrativo contiene información que puede ser conocida e información que debe denegarse en virtud de causa legal, se dará acceso a la primera y no a la segunda, f) Principio de facilitación, conforme al cual los mecanismos y procedimientos para el acceso a la información de los órganos de la Administración del Estado deben facilitar el ejercicio del derecho, excluyendo exigencias o requisitos que puedan obstruirlo o impedirlo, g) Principio de la no discriminación, de acuerdo al que los órganos de la Administración del Estado deberán entregar información a todas las personas que lo soliciten, en igualdad de condiciones, sin hacer distinciones arbitrarias y sin exigir expresión de causa o motivo para la solicitud, h) Principio de la oportunidad, conforme al cual los órganos de la Administración del Estado deben proporcionar respuesta a las solicitudes de información dentro de los plazos legales, con la máxima celeridad posible y evitando todo tipo de trámites dilatorios, i) Principio del control, de acuerdo al que el cumplimiento de las normas que regulan el derecho de acceso a la información será objeto de fiscalización permanente, y las resoluciones que recaigan en solicitudes de acceso a la información son reclamables ante un órgano externo, j) Principio de la responsabilidad, conforme al cual el incumplimiento de las obligaciones que esta ley impone a los órganos de la Administración del Estado, origina responsabilidades y da lugar a las sanciones que establece esta ley, y k) Principio de gratuidad, de acuerdo al cual el acceso a la información de los órganos de la Administración es gratuito, sin perjuicio de lo establecido en esta ley.

La redacción efectuada por el legislador respecto de los principios reseñados importa ciertos saltos lógicos que, entendemos, podrán significar un esfuerzo interpretativo y que nos hacen plantearnos preguntas como las siguientes: ¿las excepciones necesariamente contempladas en leyes de quórum calificado a que hace mención la letra son identificables con "las excepciones legales" a que refiere el artículo 10 ya mencionado?, ¿refiere la letra d) a excepciones específicas o generales?, ¿el princi- pio contemplado en la letra j) será igualmente exigible cuando el órgano del Estado no considere o pondere adecuadamente la afectación de los derechos de terceros a los que alude el Artículo 20 de la ley?

El precepto referido expresa: "cuando la solicitud de acceso se refiera a documentos o antecedentes que contengan información que pueda afectar los derechos de terceros, la autoridad o jefatura o jefe superior del órgano o servicio de la Administración del Estado, requerido, dentro del plazo de dos días hábiles, contado desde la recepción de la solicitud que cumpla con los requisitos, deberá comunicar mediante carta certificada, a la o las personas a que se refiere o afecta la información correspondiente, la facultad que les asiste para oponerse a la entrega de los documentos solicitados, adjuntando copia del requerimiento respectivo. Los terceros afectados podrán ejercer su derecho de oposición dentro del plazo de tres días hábiles contado desde la fecha de notificación. La oposición deberá presentarse por escrito y requerirá expresión de causa".

La construcción del Artículo 20 es igualmente compleja, pues al estar en presencia de la solicitud de entrega de información pública que puede afectar los derechos de un tercero, probablemente su intimidad, privacidad u honra, resulta difícil imaginar cómo podrá en su solicitud que esta información no sea entregada, incluir fundamentos que no impliquen necesariamente divulgarla al explicar por qué no quiere que sea entregada.

\section{CAUSALES DE SECRETO O RESERVA}

Estas causales se encuentran en el Artículo 21 y hacen referencia, como ya se explicó, a materias tales como la actividad de prevención, investigación y netamente jurisdiccional, antecedentes o deliberaciones previas a la adopción de una resolución, medida o política, sin perjuicio que los fundamentos de aquellas sean públicos una vez que sean adoptadas, afectación de derechos de las personas, particularmente "tratándose de su seguridad, su salud, la esfera de su vida privada o derechos de carácter comercial o económico", defensa nacional o la manten- 
ción del orden público o la seguridad pública, afectación del interés nacional, "en especial si se refieren a la salud pública o las relaciones internacionales y los intereses económicos o comerciales del país" y cuando se trate de documentos, datos o informaciones que una ley de quórum calificado haya declarado reservados o secretos, de acuerdo a las causales señaladas en el artículo $8^{\circ}$ de la Constitución Política.

Como es obvio de esta enumeración, muchos de los conceptos vertidos son de manifiesta indeterminación y aluden a una numerosa cantidad de preceptos legales, sino también reglamentarios, por lo cual las excepciones a la entrega de información serán harto más amplias que las pretensiones del artículo $8^{\circ}$ de la Constitución, en referencia con las leyes de quórum calificado que declaren documentos secretos o reservados.

\section{CONSEJO PARA LA TRANSPARENCIA}

El Artículo 31 del Proyecto crea este organismo que será absolutamente clave en la determinación real de la normativa que nos ocupa y en su verdadera aplicabilidad, entidad que será constituida como una corporación autónoma de derecho público, con personalidad jurídica y patrimonio propio y que tendrá, según el Artículo 32, "por objeto promover la transparencia de la función pública, fiscalizar el cumplimiento de las normas sobre transparencia y publicidad de la información de los órganos de la Administración del Estado, y garantizar el derecho de acceso a la información".

Tal función general, que se pormenoriza en el artículo 33, incluirá por ejemplo: "Formular recomendaciones a los órganos de la Administración del Estado tendientes a perfeccionar la transparencia de su gestión y a facilitar el acceso a la información que posean y "Proponer al Presidente de la República y al Congreso Nacional, en su caso, las normas, instructivos y demás perfeccionamientos normativos para asegurar la transparencia y el acceso a la información", además de "velar por la debida reserva de los datos e informaciones que conforme a la Constitución y a la ley tengan carácter secreto o reservado", lo cual da al
Consejo un gran poder no solo para resolver controversias - no olvidemos que se podrán revisar sus decisiones puntuales sobre entrega de información por la Corte de Apelaciones respectiva- sino para hacer una verdadera planificación de materias de información pública en el país,

El Artículo 36 contempla que "La dirección y administración superiores del Consejo corresponderán a un Consejo Directivo integrado por cuatro consejeros designados por el Presidente de la República, previo acuerdo del Senado, adoptado por los dos tercios de sus miembros en ejercicio. El Presidente hará la proposición en un solo acto y el Senado deberá pronunciarse respecto de la propuesta como una unidad. Los consejeros durarán seis años en sus cargos pudiendo ser designados solo para un nuevo período. Se renovarán por parcialidades de tres años" y podrán ser removidos "por la Corte Suprema, a requerimiento del Presidente de la República, de la Cámara de Diputados mediante acuerdo adoptado por simple mayoría, o a petición de diez diputados, por incapacidad, mal comportamiento o negligencia manifiesta en el ejercicio de sus funciones" (Artículo 38).

De acuerdo al Artículo 37 "No podrán ser designados consejeros los diputados y los senadores, los miembros del Tribunal Constitucional, los Ministros de la Corte Suprema, consejeros del Banco Central, el Fiscal Nacional del Ministerio Público, ni las personas que conforman el alto mando de las Fuerzas Armadas y de las Fuerzas de Orden y Seguridad Pública". Además, estos cargos de consejeros serán incompatibles con los de "ministros de Estado, subsecretarios, intendentes y gobernadores; alcaldes y concejales; consejeros regionales; miembros del Escalafón Primario del Poder Judicial; secretario y relator del Tribunal Constitucional; fiscales del Ministerio Público; miembros del Tribunal Calificador de Elecciones y su secretario-relator; miembros de los tribunales electorales regionales, sus suplentes y sus secretarios-relatores; miembros de los demás tribunales creados por ley; funcionarios de la Administración del Estado, y miembros de los órganos de dirección de los Partidos Políticos". 


\section{EXCEPCIONES A LA ENTREGA DE INFORMACIÓN PREVISTAS EN OTRAS LEYES}

Es destacable, en el marco de la complejidad de las excepciones para la entrega de información, revisar el artículo $1^{\circ}$ Transitorio del Proyecto, el cual preceptúa que "De conformidad a la disposición cuarta transitoria de la Constitución Política, se entenderá que cumplen con la exigencia de quórum calificado, los preceptos legales actualmente vigentes y dictados con anterioridad a la promulgación de la ley No 20.050, que establecen secreto o reserva respecto de determinados actos o documentos, por las causales que señala el artículo $8^{\circ}$ de la Constitución Política”.

\section{COMENTARIOS FINALES}

Sin duda es un avance significativo para Chile considerar como Bases de la Institucionalidad la probidad, la transparencia y el acceso a la información pública, elementos que no se pueden dejar de lado o en un lugar secundario si se pretende combatir eficazmente la corrupción, preservar las instituciones y entender la democracia como un verdadero proceso participativo.

La tarea legislativa de cuatro años para recoger legislativamente estos principios y modernizar la normativa sobre acceso a la información pública se encuentra próxima a culminar, en un proyecto que ha tenido varias adiciones y modificaciones a través del tiempo y que aún nos suscita dudas interpretativas, al establecer por una parte fuertes obligaciones y procedimientos rigurosos, pero por la otra carecer de un diseño claro de implementación e integrar una serie de excepciones que son de geometría totalmente variable y que remiten a otras muchas normas de espíritu y redacción muy disímil.

$\mathrm{Si}$ el Proyecto, finalmente, es promulgado como está, consideramos que será trascendente en él y una medida asociada con el éxito o fracaso de la Ley el proveer los recursos necesarios para que pueda operar en cuanto a las plataformas y medios que se brinden al público con la información requerida, como asimismo una acción particularmente mesurada del Consejo de la Transparencia para resolver e interpretar los preceptos oscuros o contradictorios y una poderosa decisión legislativa para enfatizar que el acceso a la información de interés público sea la regla general de nuestro sistema, ello vinculado al Artículo 19 No 12 de la Constitución y nuestros compromisos internacionales en esta materia, lo que implicará no solo entregar la información pública a todas las personas con el lógico límite consagrado en la Carta Fundamental, sino desterrar definitivamente las interferencias que a la libertad de ofrecer y de buscar información imponen aún hoy normas penales absolutamente incompatibles con el marco constitucional de la libertad de expresión, como es el caso del artículo 161-A del Código Penal.

Buscar una solución armoniosa para el conflicto al que inicialmente nos referíamos y considerar en la realidad que contar con información adecuada nos permite pensar y resolver mejor, preservará por una parte aquellos aspectos que tenemos pleno derecho o necesidad de guardar en reserva o secreto y, por otra parte, nos hará superar el miedo al escrutinio, el temor a la verdad y la resistencia a rendir cuentas en público de aquello que se decide y ejecuta precisamente al servicio de ese público. 